\title{
La traducció en l'ensenyament de llengües: un recurs exclòs de les aules del mètode directe?
}

\author{
Translation in Language Teaching: an excluded resource from the \\ Direct Method classrooms?
}

\author{
Beatriz Reverter Oliver \\ Universitat de València
}

\begin{abstract}
Resum
Tradicionalment s'ha pensat que la traducció com a eina a l'aula de llengües estrangeres va quedar desaconsellada en el mètode directe. Així, des de llavors, molts docents han defensat la idea que la traducció és un recurs nociu per ensenyar idiomes, encara que, segons Cook (2010), no hi ha evidències que ho hagin provat científicament. Abans de continuar acceptant aquesta creença heretada del mètode directe, pensem que és necessari revaluar si la traducció va ser rebutjada per tots els seus exponents i si va ser realment possible excloure-la de les aules del moment. Per tant, l'objectiu d'aquest article és dur a terme una revisió teòrica sobre què va ser, quan i per què va sorgir el mètode directe, quin paper es reconeixia a la traducció dins d'aquest mètode, quina posició van adoptar els principals teòrics que el recolzaven i si aquests plantejaments van ser vertaderament aplicables a l'aula.
\end{abstract}

Paraules clau: Traducció com a eina didàctica; Ensenyament de llengües estrangeres; Mètode directe; Revisió teòrica

\begin{abstract}
Translation as a tool within the foreign language classroom has traditionally been thought to be discouraged in the Direct Method. Thus, since then, many teachers have defended the idea that translation is a harmful resource for teaching languages, although, according to Cook (2010), there is no scientifically-proven evidence. Rather than continuing to accept this belief inherited from the Direct Method, we think it is necessary to reevaluate whether translation was rejected by all its exponents and whether it was really possible to exclude it from the classrooms of the time. Therefore, the aim of this article is to carry out a theoretical review of what was the $\mathrm{Di}$ rect Method, when and why it emerged, what role was recognized for translation within it, what position was adopted by the main theorists who supported it, and whether these approaches were truly applicable in the classroom.
\end{abstract}

Keywords: Translation as a Didactic Tool; Foreign Language Teaching; Direct Method; Theoretical Review 


\section{INTRODUCCIÓ}

El paper de la traducció com a eina didàctica en l'ensenyament de llengües estrangeres (LE) és una qüestió que ha provocat postures enfrontades entre acadèmics i docents durant molt de temps. Tot i que alguns teòrics (vegeu Cook, 2010; Duff, 1989; Kerr, 2014; Lavault, 1985, entre altres) han defensat els seus beneficis, aquesta eina sembla haver estat menysvalorada i refusada per altres (vegeu Brooks, 1964; Gatenby, 1967; Lado, 1964; Newson, 1998, per exemple), així com també per una gran part de la comunitat docent de LE al llarg del segle XX. Així mateix, encara que la situació podria estar canviant paulatinament al segle XXI, alguns professors de llengües $-\mathrm{o}$, inclús, alguns docents de programes universitaris de formació del futur professorat de LE- continuen desaconsellant la traducció com a recurs pedagògic avui dia, fins i tot titllant el seu ús de mala praxi professional.

Malgrat la visió negativa de la traducció que encara conserven alguns, Cook (2010, p. 3) explica que, en realitat, aquesta eina mai no ha quedat completament bandejada de les aules de LE —ni tan sols de les suposadament monolingües-, ja que, al cap i a la fi, molts docents l'han considerada d'utilitat en la pràctica, raó per la qual s'ha seguint emprant encara que el seu ús no es reconegués oficialment. Al fil d'aquesta idea, en un estudi anterior (Reverter Oliver, 2019), deixem constància de com la majoria dels docents d'anglès de les Escoles Oficials d'Idiomes de la Comunitat Valenciana declaren obertament fer servir la traducció quan la necessiten. Tanmateix, constatem també les reticències d'alguns professors a reconèixer que sí en fan ús, així com les justificacions d'altres que afirmen utilitzar-la, encara que assumeixen que no s'hauria de fer. També podem remarcar com alguns dels docents que no la permeten creuen que els seus companys tampoc ho fan, tot i que els resultats apunten precisament al contrari. És igualment destacable com els professors que neguen per complet el seu ús ho justifiquen esgrimint algunes de les crítiques contràries a l'ús de la traducció que tradicionalment s'han acceptat com a vertaderes, encara que ja han estat qüestionades i rebatudes en treballs com el de Zabalbeascoa (1990), Malmkjaer (1998), García-Medall (2001) o Carreres (2006). Per tant, el nostre estudi (Reverter Oliver, 2019) es podria prendre com un exemple que evidencia com la traducció s'empra per una gran part de professors, malgrat que altres encara continuïn veient-la com un recurs perjudicial i defensant que s'exclogui de les aules de LE.

Contràriament a la creença que la traducció és una eina poc eficaç o fins i tot nociva, autors com ara Lavault (1985), Zabalbeascoa (1990), Weschler (1997), Cook (2001), Kelleher (2013) o Kerr (2014), entre altres, defensen que la llengua 
materna (LMA) ${ }^{1}$ és un excel-lent recurs en l'aprenentatge de la LE i remarquen que els alumnes mai no han deixat d'experimentar la necessitat ni el desig de recórrer a ella o de traduir per comprendre millor i assimilar la llengua d'estudi. De fet, Weschler (1997, en línia) o Kerr $(2014$, p. 5) es pregunten si és possible realment obligar els alumnes a no pensar en la LMA quan aprenen la LE. De la mateixa manera, Zabalbeascoa (1990, p. 77) assegura que traduir és una activitat natural i irreprimible per als estudiants, els quals senten la necessitat de trobar la traducció de tot el que aprenen. Així mateix, Harvey (1996), Manyak (2004) o Cummins (2007) defensen que la traducció no només té beneficis en l'aprenentatge de una LE, sinó que també permet consolidar els coneixements de la LMA, la qual cosa guarda una clara relació amb el desenvolupament de la competència plurilingüe, recollida al Marc comú europeu de referència per a les llengües (MCER) (Consell d'Europa, 2001) i al Marc europeu de referència per als enfocaments plurals de les llengües i les cultures (MAREP) (Candelier et al., 2013). A més d'això, en les últimes dècades han proliferat els estudis que evidencien com la traducció escrita i audiovisual són eines que permeten potenciar l'aprenentatge de la LE (Delisle i LeeJahnke, 1998; Deller i Rinvolucri; 2002; Duff, 1989; Incalcaterra McLoughlin et al., 2018; Kerr, 2014; Laviosa i Cleverton, 2006; Leonardi, 2010; Lertola, 2019; Malmkjaer, 1998, 2004; Soler Pardo, 2017, 2020; Talaván, 2013, 2019; Torralba Miralles, 2018, 2020; Vanderplank, 2016; Witte et al., 2009, entre molts altres). D'altra banda, també al MCER (Consell d'Europa, 2001) i al Companion Volume (Consell d'Europa, 2018) es reconeix que la traducció i la interpretació són part de l'activitat comunicativa de mediació i es destaca la importància d'aquestes activitats en la societat actual, no només per als professionals de la traducció, sinó per a tots els parlants o usuaris de diverses llengües. En conseqüència, creiem que l'escenari actual evidencia com la traducció no tindria per què estar bandejada de les aules de LE, la qual cosa ens du a preguntar-nos d'on sorgeix, doncs, la creença que aquesta eina és perjudicial com a recurs didàctic en l'ensenyament d'idiomes.

D'acord amb Torralba Miralles (2019, p. 230), la traducció va quedar rebutjada a l'aula de LE a partir del sorgiment del mètode directe. Així, les idees defensades en el si d'aquest mètode semblen haver estat tan fortament assumides al llarg dels anys que han perdurat pràcticament fins als nostres dies. Tanmateix, abans d'acceptar i defensar avui dia que la traducció s'ha evitar en l'ensenyament de llengües, pensem que és necessari revisar com es van originar els plantejaments

\footnotetext{
${ }^{1}$ Com a proposta personal, advoquem per la utilització de les sigles LMA per referir-nos a la llengua materna amb la intenció de no confondre el lector amb el terme llengua meta, freqüent quan es parla de qüestions traductològiques. A més a més, la llengua meta d'una traducció no sempre coincideix amb la llengua materna, per la qual cosa convé no confondre aquests termes.
} 
del mètode directe per tal d'entendre si la postura contrària a l'ús de la traducció estava fonamentada en teories científiques sòlides, si va ser acceptada per tots els exponents del mètode o si va resultar aplicable en la realitat de les aules. Si no fos així, ens preguntem si hi hauria, doncs, alguna raó que justifiqués el rebuig a la traducció si ja en el moment de major apogeu del mètode directe no s'hagués pogut provar que aquesta fos una eina perjudicial dins l'aula d'idiomes.

L'objectiu del present article és, doncs, dur a terme una revisió teòrica sobre què és, quan i per què va sorgir el mètode directe, quines eren les principals propostes per ensenyar la LE i quina era la postura que van adoptar els seus exponents pel que fa al paper de la traducció. Això ens permetrà entendre millor les idees defensades llavors per tal de reflexionar sobre si sembla lògic continuar acceptant en l'actualitat aquelles premisses contràries a l'ús de la traducció, sobretot si tenim en compte els avanços posteriors en la didàctica de llengües que hem esmentat.

\section{EL SORGIMENT DEL MÈTODE DIRECTE}

D'acord amb Cook (2010, p. 15), el rebuig a la traducció es produeix com a consequiència de les crítiques que va rebre el mètode gramàtica-traducció. Aquest darrer mètode, sorgit en el segle XIX i heretat de l'estudi de les llengües clàssiques, proposava l'ensenyament de la LE a partir de lectures, de l'estudi de regles gramaticals - explicades deductivament i en la LMA per tal d'assegurar una millor comprensió- i de la memorització de llistes bilingües de vocabulari. Posteriorment, aquests coneixements teòrics es practicaven mitjançant exercicis de traducció d'oracions creades explícitament a aquest efecte. En conseqüència, la faceta oral de la llengua gairebé no era practicada, raó per la qual els professors que empraven aquest mètode eren acusats de no dominar la llengua que impartien (Richards $\mathrm{i}$ Rodgers, 2003, pp. 15-16; Cook, 2010, p. 10). Per tant, la LMA representava un paper essencial en aquest mètode, ja que, d'acord amb Stern (1983, p. 455), es mantenia com a referència tant en les explicacions gramaticals com en les traduccions.

A finals del segle XIX, la falta de resultats satisfactoris derivats del mètode gramàtica-traducció i la necessitat de la població europea per comunicar de forma oral van dur a la recerca de noves propostes per a l'ensenyament d'idiomes. És llavors quan alguns investigadors en lingüística i fonologia, com ara Viëtor, Klinghardt, Jespersen o Sweet, defensaren que la llengua era essencialment oral i que, per tant, s'havia de potenciar el desenvolupament aquestes habilitats. Així, es va proposar un ensenyament centrat en l'estudi de vocabulari, fonètica i gramàtica, i 
en l'ús de textos complets en lloc d'oracions artificioses i descontextualitzades, seguint les teories psicològiques associacionistes. Al mateix temps, als Estats Units, la necessitat de les persones no nadiues per aprendre anglès va dur a la creació de les escoles Berlitz, on s'implementava un mètode basat en postulats semblants i que, segons Cook, seria el precursor del mètode directe. Paral-lelament a aquestes propostes, també hi havia un especial interès per desenvolupar un mètode naturalista, és a dir, basat en l'observació de l'aprenentatge de la LMA. És en aquest escenari on naix el mètode directe (Richards i Rogers, 2003, pp. 19-20; Cook, 2010, pp. 67).

\section{ELS PLANTEJAMENTS DEL MÈTODE DIRECTE}

El principal objectiu del mètode directe consistia a aconseguir el domini de la LE, prioritzant les habilitats orals i defugint de l'estudi d'oracions inventades i descontextualitzades en benefici de l'ús de textos connectats i amb sentit complet. Així mateix, la pronunciació va adquirir especial atenció, per la qual cosa la figura del professor nadiu va començar a alçar-se per damunt dels docents que empraven el mètode anterior i que, com dèiem, en ocasions eren acusats de no dominar la llengua que impartien. Per això, encara que les habilitats escrites també eren practicades, les lliçons es centraven en la presentació de vocabulari i d'oracions d'ús quotidià, introduïdes oralment i en la LE directament mitjançant l'associació amb imatges, objectes o idees pels conceptes abstractes. A més, la gramàtica es considerava igualment rellevant, encara que era estudiada de manera inductiva (Germain, 1993, p. 127; Richards i Rodgers, 2003, pp. 17-22; Cook, 2010, pp. 4-5).

Una de les característiques més conegudes i acceptades del mètode és que l'alumnat havia d'emprar la LE sense haver de pensar prèviament en la LMA, puix que provocava interferències que impedien l'aprenentatge eficaç. Un exemple d'aquests raonaments el trobem en el lingüista associacionista Franke, qui argumentava que l'ús de la LMA implicava que l'alumnat havia de fer una forçosa associació entre les paraules en aquesta llengua i en la LE, cosa que suposaria un complex procés psicològic (Laviosa, 2014, pp. 8-9). Això no obstant, en relació amb aquesta idea, són interessants les reflexions de Cook (2010, p. 5) quan explica que aquestes teories psicològiques de finals del segle XIX en les quals es fonamentava el mètode directe van quedar rebatudes i anul-lades al llarg del segle XX. En canvi, les idees reformistes sobre l'ensenyament de LE que van sorgir d'aquelles teories no han estat qüestionades posteriorment en el camp de la didàctica de llengües, sinó que, pel contrari, s’han acceptat sense més reflexió. Així doncs, creiem 
que no semblaria lògic assumir que la LMA és perjudicial basant-nos en teories de les quals la psicologia ja es va desmarcar fa dècades.

\section{LA TRADUCCIÓ EN EL MÈTODE DIRECTE}

Els estudis que hem consultat sobre enfocaments i mètodes de la didàctica de LE (Germain, 1993; Cortés Moreno, 2000; Richards i Rodgers, 2003; Larsen-Freeman i Anderson, 2011) sostenen que el mètode directe advocava per l'evitació de la traducció. Encara que pensem que no es pot negar que aquest va ser el corrent de pensament principal del moment, s'hauria de destacar que aquestes excel-lents obres no estan centrades en l'anàlisi del paper de la traducció en els diferents mètodes, sinó que, com ja denunciava Cook (2010, p. 21), normalment recullen el que s'ha dit sobre aquesta eina durant dècades: pràcticament res. Per tant, nosaltres hem fet una revisió teòrica al respecte amb l'objectiu d'aclarir si és cert que la traducció va quedar completament exclosa de les aules del mètode directe o si els seus exponents van coincidir en la visió negativa d'aquest recurs.

Així, Cook (2010, p. 5) afirma que, en realitat, els teòrics reformistes no tenien una actitud fanàtica pel que feia a l'ús de la traducció, sinó que, fins i tot, alguns d'ells en permetien un ús judiciós. Així, Laviosa (2014, pp. 8-9) explica que aquest era el cas, per exemple, de Sweet (1900, pp. 199-200), qui es mostrava en desacord amb Franke i amb l'argument que fer servir la LMA provoqués un complex procés d'associació amb les paraules de la nova llengua. D’acord amb Sweet, aquest procés no sempre és complex, donat que hi ha paraules tan properes sobretot entre llengües semblants- que l'associació es dóna de manera instantània i sense cap esforç. A més a més, Sweet defensava que l'ús exclusiu de la LE i d'imatges en determinats casos podia resultar inadequat, per exemple, en tractar d'explicar el vocabulari d'alguns conceptes abstractes o de trobar una paraula concreta utilitzant només un element visual. En conseqüència, Sweet (1900, p. 202) afirmava: "We translate the foreign words and phrases into our language simply because this is the most convenient and at the same time the most efficient guide to their meaning". Igual que Sweet, també, el lingüista danès Jespersen (1904) va arribar a acceptar la traducció com una eina d'utilitat, segons ho explica Torralba Miralles (2016, p. 16).

Així doncs, d'acord amb Cook (2010, p. 6), la primera corrent de rebuig a la traducció es pot trobar a les escoles Berlitz. Així ho demostra la següent citació del seu fundador (Berlitz, 1898, pp. 2-3): 
(i) Translation wastes valuable language learning time which should be devoted entirely to the foreign language; (ii) translation encourages mother-tongue interferences; (iii) all language are different ('every language has its peculiarities, its idiomatic expressions and turns, which cannot possibly be rendered by translation').

Aquesta postura en contra de l'ús de la traducció era, precisament, una de les principals formes d'oposició al mètode gramàtica-traducció. Per aquest motiu, per controlar i garantir que no fos utilitzada, en les escoles Berlitz es van implementar mesures tan estrictes com ara la utilització de micròfons a les aules (Cook, 2010, pp. 6-7). Tanmateix, encara que, com dèiem, aquestes idees han perdurat durant dècades, Cook (2010, p. 21) assegura que no hi ha estudis que hagin demostrat la seva validesa amb proves científiques. A més d'això, l'autor (2010, p. 4) argumenta que la traducció es va prohibir en la pràctica i només després es va tractar de justificar teòricament, la qual cosa ens fa dubtar del rigor científic d'aquesta proposta. Igualment, Martín Martín (2001, p. 160) remarca, a partir dels treballs de Widdowson (1992), Phillipson (1992) i Sheen (2000), els interessos econòmics que hi havia rere la creació dels mètodes monolingües, la qual cosa també fa sospitar que, en realitat, aquestes propostes no tenien una base teòrica que recolzés els seus planejaments, sinó que atenien més aviat a qüestions comercials: inauguració d'escoles privades on s'impartien mètodes monolingües o la publicació i distribució de nous llibres de text només en la LE, els quals eren més rentables. També Kerr (2014, p. 3) es mostra en consonància amb aquesta idea quan afirma que el mètode Berlitz va suposar un gran èxit comercial, però que les seves propostes van gaudir de major acolliment entre el públic general que entre els professionals de les llengües.

Tot i la mancança d'evidències científiques per defensar aquesta postura, les principals línies de pensament del mètode directe instaven a refusar la traducció. Amb tot, Puren (2012, p. 124) evidencia com aquesta eina tampoc no es va poder suprimir del tot en la pràctica de les aules. L'autor assegura que les recomanacions de la instrucció de 1908 a França - la qual reconeixia oficialment que el mètode directe s'havia d'emprar dins l'educació secundària francesa i establia el tipus de pràctiques que s'havien de dur a terme en l'ensenyament-, admetien l'ús de la traducció en la primera classe perquè els estudiants feren preguntes, encara que en les lliçons posteriors no es permetia aquest ús ni per part del professorat ni de l'alumnat. No obstant això, Puren aclareix que la instrucció també recollia la possibilitat de fer servir una traducció que no fos paraula per paraula — com al mètode gramàtica-traducció- per tal d'aclarir conceptes o explicar la gramàtica si la LE no resultava un recurs suficientment efectiu. En altres paraules, no sembla que el rebuig fos contra tot tipus de traducció, sinó contra les pràctiques que es duien a 
terme en el mètode gramàtica-traducció, una qüestió de la qual ja va donar compte Cook (2010). Igualment, Puren (2012, pp. 123-125) explica que la traducció va arribar a emprar-se en aquell moment com un mecanisme d'avaluació de la comprensió de lectures, cosa que semblava especialment útil per als alumnes amb majors dificultats, pels qui entendre els nous conceptes sense recórrer a la LMA podia arribar a ser contraproduent, especialment si no dominaven bé la LE. Així, en paraules de l'autor, la major part dels teòrics francesos del moment ja eren conscients que una prohibició absoluta de la LMA i la traducció no era ni desitjable ni aplicable en la pràctica.

Igual que Puren, Lavault (1985, pp. 15-16) també afirma que la ruptura total amb la traducció no va arribar a donar-se en la realitat de les aules del mètode directe, atès que, per exemple, a França es conservava com un exercici essencialment literari. L'autora afegeix, basant-se en Bouton (1974), que els alumnes adolescents i adults reorganitzen l'experiència que presenta la situació d'adquisició de la nova llengua mitjançant la LMA. De la mateixa manera, les suposades associacions mentals directes que s'havien de fer entre un objecte i una paraula en la LE tampoc no impedien que es donés una associació mental amb la paraula en la LMA, cosa difícilment controlable pel docent, encara que estigués prohibit verbalitzar aquest pensament.

Per tant, evitar l'ús de la LMA i la traducció va ser una qüestió difícil d'aconseguir en la pràctica ja en aquell moment, sobretot si el docents havien de seguir estrictament un mètode que no satisfeia les necessitats o desitjos de l'alumnat. Així ho defèn Lavault (1985, pp. 22-23) quan explica que molts professors de l'educació secundària francesa van arribar a experimentar frustració per haver de complir estrictament amb les premisses d'un mètode monolingüe que en la pràctica no resultava tan efectiu com s'havia promès. També Brown $(1973$, p. 5) va recollir, a partir de l'observació de classes on s'implementava el mètode directe, com el professorat experimentava dificultats per fer comprendre el significat d'algunes paraules fent un ús exclusiu de la LE quan, en opinió de l'autor, una senzilla traducció de la paraula hauria estat molt més eficaç. Així mateix, Besse (1970) o Antier et al. (1972) també van assegurar que l'aplicació estricta dels principis que impedien l'ús de la LMA i la traducció podia resultar contraproduent, ja que dificultava la tasca del professor i entorpia l'aprenentatge en determinants casos, per exemple, per ensenyar el vocabulari tècnic o explicar conceptes abstractes, on, en moltes ocasions, era necessari fer servir més vocabulari, el qual solia ser més complex encara. 
Tenint en compte tot l'anterior, podríem dir que, dins les aules del mètode directe —el qual es considera un dels mètodes monolingües més importants de la didàctica de llengües-, la traducció ja es veia com un recurs més efectiu en determinants casos que no la utilització forçosa de la LE en tot moment. Per aquesta raó, no es va poder eliminar de les aules per complet, així com tampoc, quan s'intentava, els resultats semblaven tan satisfactoris com es podria pensar a priori.

\section{CONCLUSIONS}

Com ja argumentàvem al començament de l'article, hem cregut necessari dur a terme una revisió teòrica sobre el paper de la traducció en el mètode directe, ja que, segons Torralba Miralles (2019), la visió negativa al voltant d'aquest recurs té el seu origen en les idees defensades en el si d'aquest mètode. Per tant, creiem que un primer pas per adoptar - $\mathrm{O}$ no- una postura contrària a l'ús de la traducció avui dia i continuar reproduint les idees reformistes és revisar si aquells plantejaments del mètode directe poden seguir tenint validesa en els nostres dies i, fins i tot, si ja en aquell moment van ser acceptats o ben acollits pels teòrics i docents.

Així, d'una banda, hem pogut comprovar com, en realitat, durant l'època en què el mètode directe s'emprava a Europa, la traducció no va poder quedar completament bandejada de les aules, sinó que, més aviat, va passar a tenir un paper discret, donat que, en realitat, alguns docents continuaven considerant-la de major utilitat en determinants casos que no l'ús exclusiu de la llengua d'estudi. A més, la idea que evitar la traducció potencia un aprenentatge més eficaç de la LE no estava fonamentada en teories científiques, sinó que, aparentment, es va fer servir per respondre a una estratègia comercial per impulsar el monolingüisme. Així doncs, malgrat els bons resultats que prometien els defensors del mètode directe, alguns docents experimentaren sentiments de frustració per haver de complir amb la imposició del monolingüisme dins l'aula, tot i que no satisfeia les necessitats de l'alumnat.

D'altra banda, recordem com Cook (2010, pp. 15, 21) afirma que no existeix una justificació des del punt de vista científic que hagi pogut provar que la traducció sigui un recurs nociu per l'aprenentatge de la LE, sinó que, senzillament, s'ha ignorat el seu potencial en haver donat per vàlides les crítiques al mètode gramàtica-traducció i haver-les utilitzades com arguments contra tot ús de la traducció. Tanmateix, l'autor insisteix que entendre l'ús particular que es feia de la traducció en el mètode gramàtica-traducció com tota explotació possible de la traducció sembla un argument poc adequat. Així mateix, l'autor $(2010$, p. 5) defèn també 
que les idees reformistes sobre l'aprenentatge de la llengua no han estat pràcticament qüestionades durant quasi un segle, encara que les teories lingüístiques i psicològiques que defenien els reformistes han quedat anul-lades amb els avanços posteriors en els dos camps.

D'altra banda, encara que, tradicionalment, el moviment reformista representa el inici de l'ensenyament monolingüe en la didàctica de llengües, es podria dir que tampoc tots els teòrics defensors dels plantejaments reformistes i del mètode directe es mostraven d'acord amb la idea de refusar la traducció en tot moment, ja que reconeixien que, en ocasions, aquesta eina resultava més efectiva que no l'ús exclusiu de la LE. Així ho creien, per exemple, autors com ara Sweet (1900) o Jespersen (1904). També Puren (2012) recull com, fins i tot en el moment de major hegemonia del mètode directe a França, els experts en didàctica de llengües sabien que una imposició absoluta de la LE no era recomanable ni possible en la pràctica.

En definitiva, es podria dir que la traducció ha estat considerada una eina dolenta en l'ensenyament de LE durant gran part del segle XX i, parcialment, del segle XXI, encara que el seu rebuig no s'ha pogut justificar amb evidències científiques ni mitjançant les experiències pràctiques dels docents. Així doncs, aquells que encara defensen el seu desnonament de les aules podrien estar, presumiblement, acceptant unes creences heretades des de principis del segle XX, les quals no s'han demostrat com a vertaderes per la comunitat científica. Per tant, pensem que seria necessari un major volum d'estudis que analitzaren si la traducció és realment un recurs perjudicial per poder adoptar una postura contrària al seu ús. Conseqüentment, tenint en compte la feblesa dels arguments en contra de l'ús de la traducció defensats en el mètode directe, la mancança d'estudis posteriors que demostren que aquest recurs entorpeixi realment l'aprenentatge de la LE i els bons resultats de les investigacions sobre l'aplicació de traducció escrita i audiovisual en l'ensenyament de LE que hem citat al començament d'aquest article —així com també la postura adoptada pel Consell d'Europa pel que fa a la inclusió de la traducció dins l'aula de llengües-, creiem que desaconsellar-la o prohibir-la és una postura poc encertada en l'actualitat. Per tant, esperem que la nostra aportació ací pugui contribuir humilment a fer reflexionar els seus detractors.

\section{REFERÈNCIES}

Antier, M., Girard, D., \& Hardin, G. (1972). Pédagogie de l'anglais. Hachette.

Berlitz, M. D. (1898). The Berlitz Method for Teaching Modern Languages. English Part. First Book. The Berlitz School. 
Besse, H. (1970). Problèmes de sens dans l'enseignement d'une langue étrangère. Langue française, 8(1), 62-77. https://doi.org/10.3406/lfr.1970.5528

Bouton, C. P. (1974). L'acquisition d'une langue étrangère. Klincksieck.

Brooks, N. (1964). Language and learning: Theory and Practice ( $2^{a}$ Ed.). Harcourt Brace \& World.

Brown, R. (1973). A First Language: The Early Stages. Harvard University Press.

Candelier, M., Camilleri-Grima, A., Castellotti, V., de Pietro, J-F., Lörincz, I., Meissner, F-J., Noguerol, A., \& Schröder-Sura, A. (2013). Marco de Referencia para los Enfoques Plurales de las Lenguas y de las Culturas. Competencias y recursos. European Centre for Modern Languages. https://carap.ecml.at/Portals/11/documents/CARAP_version3_ES \% 2015072010.pdf

Carreres, À. (2006, desembre). Strange bedfellows. Translation and Language Teaching: the Teaching of Translation into L2 in Modern Languages Degrees; Uses and Limitations [Comunicació]. 6th Symposium on Translation, Terminology and Interpretation in Cuba and Canada, Toronto, Canadà. http://www.cttic.org/ACTI/2006/papers/Carreres.pdf

Consell d'Europa. (2001). Common European Framework of Reference for Languages: Learning, Teaching, Assessment (CEFR). Cambridge University Press. https://rm.coe.int/1680459f97

Consell d'Europa. (2018). Common European Framework of Reference for Languages: Learning, Teaching, Assessment. Companion Volume with New Descriptors. Consell d'Europa. https://rm.coe.int/cefr-companion-volume-with-new-descriptors-2018/1680787989

Cook, G. (2010). Translation in Language Teaching. Oxford University Press.

Cook, V. (2001). Using the First Language in the Classroom. Canadian Modern Language Review, 57(3), 402-423. https://doi.org/10.3138/cmlr.57.3.402

Cortés Moreno, M. (2000). Guía para el profesor de idiomas: didáctica del español y segundas lenguas. Octaedro.

Cummins, J. (2007). Rethinking monolingual instructional strategies in multilingual classrooms. Canadian Journal of Applied Linguistics, 10(2), 221-240. http://www.aclacaal.org/wpcontent/uploads/2013/08/7-vol-10-no2-art-cummins.pdf

Delisle, J., \& Lee-Jahnke, H. (Dirs.). (1998). L'enseignement de la traduction et la traduction dans l'enseignement. Les Presses de l'Université d'Ottawa, University of Ottawa Press.

Deller, S., \& Rinvolucri, M. (2002). Using the Mother Tongue: Making the Most of the Learner's Language. Delta Publishing.

Duff, A. (1989). Translation. Oxford University Press.

García-Medall, J. (2001). La traducción en la enseñanza de lenguas. Hermeneus. Revista de Traducción e Interpretación, 3, 1-18. https://recyt.fecyt.es/index.php/HS/article/view/6083

Gatenby, E. V. (1967). Translation in the Classroom. W. R. Lee (Ed.), E.L.T. Selections 2: Articles from the Journal English Language Teaching (pp. 65-70). London University Press.

Germain, C. (1993). Évolution de l'enseignement des langues, 5000 ans d'histoire. Clé International.

Harvey, M. (1996). A Translation Course for French-speaking Students. P. Sewell \& I. Higgins (Eds.), Teaching Translation in Universities. Present and Future Perspectives (pp. 45-66). Association for French Language Studies in association with the Centre for Information on Language Teaching and Research.

Incalcaterra McLoughlin, L., Lertola, J., \& Talaván, N. (Eds.). (2018). Audiovisual Translation in Applied Linguistics: Educational Perspectives. Translation and Translanguaging in Multilingual Contexts, 4(1). https://doi.org/10.1075/ttmc.4.1 
Jespersen, O. (1904). How to Teach a Foreign Language. Allen and Uwin.

Kelleher, M. (2013). Overcoming the First Language Taboo to Enhance Learning a Foreign Language. Procedia-Social and Behavioral Sciences, 93, 2037-2042. https://doi.org/10.1016/j.sbspro.2013.10.161

Kerr, P. (2014). Translation and Own-language Activities. Cambridge University Press.

Lado, R. (1964). Language Teaching: A Scientific Approach. McGraw-Hill.

Larsen-Freeman, D., \& Anderson, M. (2011). Techniques and Principles in Language Teaching ( $3^{\text {a }}$ Ed.). Oxford University Press.

Lavault, E. (1985). Fonctions de la traduction en didactique des langues : apprendre une langue en apprenant à traduire. Didier Erudition.

Laviosa, S. (2014). Translation and Language Education: Pedagogic Approaches. Routledge.

Laviosa, S., \& Cleverton, V. (2006). Learning by Translating: A Contrastive Methodology for ESP Learning and Translation. Scripta Manent. Journal of the Slovene Association of LSP Teachers, 2(1), 3-12. http://www.sdutsj.edus.si/ScriptaManent/2006_1/Laviosa_Cleverton.html

Leonardi, V. (2010). The Role of Pedagogical Translation in Second Language Acquisition. From theory to practice. Peter Lang.

Lertola, J. (2019). Second Language Vocabulary Learning Through Subtitling. Revista Española de Lingüistica Aplicada, 32(2), 486-514. https://doi.org/10.1075/resla.17009.ler

Malmkjaer, K. (Ed.). (1998). Translation in Language Teaching. Language Teaching and Translation. St. Jerome Publishing.

Malmkjaer, K. (Ed.). (2004). Translation in Undergraduate Degree Programmes. John Benjamins.

Martín Martín, J. M. (2001). Nuevas tendencias en el uso de la L1. Elia: Estudios de lingüística inglesa aplicada, 2, 159-170. http://institucional.us.es/revistas/elia/2/12.Jose miguel.pdf

Manyak, P. C. (2004). "What Did She Say?”: Translation in a Primary-Grade English Immersion Class. Multicultural Perspectives, 6(1), 12-18. https://doi.org/10.1207/S15327892mcp0601_3

Newson, D. (1998). Translation and Foreign Language Learning. K. Malmkjaer (Ed.), Translation and Language Teaching: Language Teaching and Translation (pp. 63-67). St. Jerome Publishing.

Phillipson, R. (1992). Linguistic Imperialism. Oxford University Press.

Puren, C. (2012). Histoire des méthodologies de l'enseignement des langues. Nathan-CLE International. (Original de 1988). https://www.aplv-languesmodernes.org/docrestreint.api/ 1849/b1a776bacb5d6ccbb0a692b19bd88566e4b5a707/pdf/puren_histoire_methodologies.pdf

Reverter Oliver, B. (2019). Inclusión del alumnado con discapacidad sensorial y traducción audiovisual en las aulas de inglés de las EEOOII de la Comunitat Valenciana. Un estudio exploratorio. [Tesi doctoral]. Universitat de València. http://roderic.uv.es/handle/10550/72472

Richards, J. C., \& Rodgers, T. S. (2003). Enfoques y métodos en la enseñanza de idiomas (2a ed.). (Trad. J. M. Castrillo). Edinumen. (Original de 2001).

Sheen, R. (2000). A response to Spada and Lightbown: "Instruction, first language influence, and developmental readiness in second language acquisition". The Modern Language Journal, 84, 102-106. https://www.jstor.org/stable/330452

Soler Pardo, B. (2017). Audiovisual Translation in the teaching of a FL: Subtitling as a Methodological Tool for Lexis acquisition. Tejuelo, 26, 163-192. https://doi.org/10.17398/1988$\underline{8430.26 .163}$ 
Soler Pardo, B. (2020). La subtitulación y el doblaje como recursos didácticos para aprender inglés como lengua extranjera utilizando el software Clipflair. Lenguaje y Textos, 51, 4156. https://doi.org/10.4995/lyt.2020.12690

Stern, H. H. (1983). Fundamental Concepts of Language Teaching. Oxford University Press.

Sweet, H. (1900). The Practical Study of Languages: A Guide for Teachers and Learners. Henry Holt and Company.

Talaván, N. (2013). La subtitulación en el aprendizaje de lenguas extranjeras. Octaedro.

Talaván, N. (2019). La traducción audiovisual como recurso didáctico para mejorar la comprensión audiovisual en lengua extranjera. DobleLe. Español Lengua Extranjera, 5, 85-97. https://doi.org/10.5565/rev/doblele.59

Torralba Miralles, G. (2016). L'aprenentatge de llengües a través de la traducció audiovisual: la subtitulació com a eina per a l' adquisició de lèxic en llengua estrangera. [Tesi doctoral]. Universitat Jaume I de Castelló. https://www.tdx.cat/handle/10803/403984

Torralba Miralles, G. (2018). Aprendizaje y perfeccionamiento de lenguas: la subtitulación en el Grado en Maestro de Educación Primaria. Revista de Lenguas para Fines Específicos, 24(2), 73-91. https://ojsspdc.ulpgc.es/ojs/index.php/LFE/article/view/881

Torralba Miralles, G. (2019). Ensenyament de llengües: el paper de la traducció al llarg de la historia. Quaderns: revista de traducció, 26, 227-238. https://www.raco.cat/index.php/QuadernsTraduccio/article/view/356299

Torralba Miralles, G. (2020). The Use of Passive and Active Subtitles in Foreign Language Teaching: A View to their Teaching Potential. Íkala, 25(1), 231-250. https://doi.org/10.17533/udea.ikala.v25n01a11

Vanderplank, R. (2016). Captioned media in foreign language learning: Subtitles for the deaf and hard-of-hearing as tools for language learning. Palgrave.

Weschler, R. (1997). Uses of Japanese (L1) in the English Classroom: Introducing the FunctionalTranslation Method. The Internet TESL Journal, 3(11). http://iteslj.org/Articles/WeschlerUsingL1.html

Widdowson, H. G. (1992). ELT and EL Teachers: Matters Arising. ELT Journal, 46(4), 333-339. https://doi.org/10.1093/elt/46.4.333

Witte, A., Harden, T., \& Ramos de Oliveira Harden, A. (Eds.). (2009). Translation in Second Language Learning and Teaching. Peter Lang.

Zabalbeascoa, P. (1990). Aplicaciones de la traducción a la enseñanza de lenguas extranjeras. Sintagma, 2, 75-86. http://www.sintagma-online.udl.cat/imatges/pdf/1990h.pdf 


\section{BEATRIZ REVERTER OLIVER}

Beatriz Reverter Oliver va obtindre el doctorat internacional en 2019 a la Universitat de València. Les seves àrees de recerca són la traducció audiovisual com a eina per a la didàctica de llengües, l'educació inclusiva dels estudiants de llengües amb discapacitat sensorial i l'accessibilitat als mitjans de comunicació.

bereo@alumni.uv.es

Reverter Oliver, B. (2021). La traducció en l'ensenyament de llengües: un recurs exclòs de les aules del mètode directe?. Bellaterra Journal of Teaching \& Learning Language \& Literature, 14(4), e900. https://doi.org/10.5565/rev/jt13.900

Rebut / Recibido / Received / Reçu: 14-04-2021

Acceptat / Aceptado / Accepted / Accepté: 10-06-2021

https://revistes.uab.cat/jtl3/ 